\title{
Characterization of the aroma and colour profiles of fortified Muscat wines: comparison of Muscat Blanc "à petit grains" grape variety with Red Muscat
}

\author{
Diva Jesus $^{1} \cdot$ Francisco M. Campos $^{1} \cdot$ Miguel Ferreira $^{2} \cdot$ José A. Couto $^{1}$
}

Received: 23 September 2016 / Revised: 21 November 2016 / Accepted: 28 December 2016 / Published online: 16 January 2017

(C) Springer-Verlag Berlin Heidelberg 2017

\begin{abstract}
Although Muscat Blanc "à petit grains" and Red Muscat grape varieties are both cultivated in the Douro Demarcated Region (Portugal), only Muscat Blanc is currently authorized for the production of the fortified wine "Moscatel do Douro". The aim of this study was to evaluate the potential of the Red Muscat grape variety to be employed in the winemaking of Douro Muscat wines. Wines of both grape varieties were produced from the 2013 and 2014 harvests, and were chemically and sensory analysed 12 and 3 months after stopping the alcoholic fermentation, respectively. The Muscat Blanc "à petit grains" variety produced musts with higher sugar content than the red variety, but the final levels of sugar and ethanol were similar in all wines owing to the control of the fermentation time. Red Muscat wines presented higher concentrations of rose oxide and nerol than Muscat Blanc "à petit grains"; however, these differences were only significant in the youngest wines. Linalool and $\alpha$-terpineol were found at higher levels in the 2013 Muscat Blanc "à petit grains" wines. No significant differences were found for the ester compounds, except for 2-phenylethanol, which was higher in the Red Muscat wines. The 12 months old wines presented a higher total concentration of esters than the younger wines. No significant differences were found for the higher alcohols composition between the two grape varieties. The chromatic analysis showed that, besides
\end{abstract}

José A. Couto

jcouto@ porto.ucp.pt

1 CBQF-Centro de Biotecnologia e Química Fina-Laboratório Associado, Escola Superior de Biotecnologia, Universidade Católica Portuguesa/Porto, Rua Arquiteto Lobão Vital, Apartado 2511, 4202-401 Porto, Portugal

2 Adega Cooperativa de Favaios, Lugar dos Pousados, 5070-265 Favaios, Portugal having a redder tone, Red Muscat wines had a higher colour intensity and a more pure/saturated colour than Muscat Blanc "à petit grains" wines. The sensory analysis did not detect significant differences in the aromatic and gustatory profiles between the two grape varieties. The Red Muscat grape variety shows great potential to be employed in the production of Muscat fortified wine either as monovarietal or in blends with Muscat Blanc "à petit grains".

Keywords Wine · Muscat Blanc · "à petit grains" · Red Muscat $\cdot$ Quality

\section{Introduction}

Muscat wines are characterized by typical floral aromas, which are mostly of grape origin. Monoterpenols, such as linalool, geraniol, nerol, citronellol, and $\alpha$-terpineol, contribute greatly to the characteristic floral aroma and flavour of the Muscat grape varieties [1-7]. Rose oxide is also an important aroma compound in Muscat, since its presence is highly correlated with the Muscat flavour of table grape cultivars [8]. Rose oxide is formed by the stereoselective reduction of geraniol to citronellol with subsequent cyclization. An increase of the geraniol reductase activity was found towards the end of grape ripening, leading to the production of rose oxide at this stage [9]. Grape aroma compounds are present in grapes as free and glycosylated forms, but only the free forms contribute directly to the aroma profile of the wines. Volatile compounds formed during the alcoholic fermentation also play an important role in the aroma profile of wines, including short chain $(\mathrm{C} 6, \mathrm{C} 8$, and C10) fatty acids and their ethyl esters and higher alcohols and their acetate esters. These esters enhance the fruity and floral aroma of wines, while higher alcohols and fatty acids, 
depending on the concentration, add complexity or contribute negatively to the aroma profile of wines [3, 7, 10-13].

Muscat Blanc "à petit grains" wines from La Mancha region (Spain) were found to have high concentrations of monoterpenes, mainly linalool, geraniol, citronellol, $\alpha$-terpineol, and nerol [4]. In the same study, hexanol was the most important C6 alcohol and 2-phenylethanol was the volatile benzene compound found in major quantity, mostly as free form; norisoprenoids were found only as bound form. Regarding the volatile compounds formed during the alcoholic fermentation, the most relevant were 3-methyl1-butanol, 2-methyl-1-butanol, 2-methyl-1-propanol, 1-propanol, acetaldehyde, methanol, ethyl acetate, isoamyl acetate, ethyl 4-hydroxybutyrate, ethyl octanoate, diethyl succinate, isobutyric acid, hexanoic acid, and octanoic acid, among others [4]. In the sensory analysis, the most intense attribute detected by tasters was described as "Muscat aroma", followed by "floral", "fresh", and "fruity" descriptors. A previous work characterized the aromatic profile of Muscat of Bornova cultivar and found B-damascenone, ethyl hexanoate, ethyl butanoate, isoamyl acetate, 2-phenyl ethyl acetate, linalool, geraniol, and 2-phenylethanol as the most characteristic aroma-active compounds of this wine $[3,14]$. Different vinification and ageing processes of Muscat wines were found to led to different aroma profiles [1].

Muscat Blanc "à petit grains" and Red Muscat varieties are cultivated in the Douro Demarcated Region (Northeast Portugal). Located in deep valleys and protected by mountains, the climate of this region is characterized by very cold winters and hot, dry summers. The soil is schistose with some granite around the edges. The fortified Muscat wine produced in this region is made from Muscat Blanc "à petit grains" variety. The Red Muscat variety is also cultivated in this region; however, it is not used for wine production due to legal restrictions. The scientific knowledge concerning this variety is very poor. One work recently revealed the polyphenol composition of red and white Muscat genotypes, but the volatile profile is scarcely known [15].

The aim of this study was to characterize the aroma and colour profiles of Red Muscat and Muscat Blanc "à petit grains" wines and to evaluate the potential of the Red Muscat variety for the production of high-quality fortified Muscat wines. Scientific data are required to support applications for the authorization of the usage of this grape variety in the production of fortified Muscat. It will be of great value to know what are the similarities and main differentiating aspects of Red Muscat in comparison to Muscat Blanc "à petit grains".

\section{Materials and methods}

\section{Wines}

Fortified wines (300 L) were made from Vitis vinifera var. Muscat Blanc "à petit grains" and Red Muscat grapes cultivated in the Douro Demarcated Region (Portugal). The fermentation time varied between 2 and 4 days depending on the time needed to obtain the desired final sugar level. The temperature of the fermentations was $19-21{ }^{\circ} \mathrm{C}$ in both vintages. The alcoholic fermentation was stopped by the addition of brandy to produce fortified sweet wines, according to the traditional vinification procedure for this style of wines. After the fermentation, the wines were kept in $20 \mathrm{~L}$ glass flasks until samples were taken for analysis. Two wines of each grape variety, corresponding to different grape ripeness levels (2 weeks difference), were prepared from the 2013 harvest. The vineyard site, sunlight exposure, and soil characteristics were equal for both grape varieties. The same procedure was followed to produce wines from the 2014 harvest (see Table 1). All wines were made in duplicate.

\section{Extraction and GC-FID analysis of free monoterpenoids, esters and volatile fatty acids}

For the extraction of monoterpenoids, a liquid-liquid extraction was done prior to the chromatographic analysis of the samples. Before extracting, 4-decanol (in methanol solution) was added, as an internal standard, to $50 \mathrm{~mL}$ of wine and the mixture was extracted with diethyl ether/hexane $(50: 50 \mathrm{v} / \mathrm{v})$, stirring in a closed flask for $5 \mathrm{~min}$. The organic phase was collected to a vial and the extraction was repeated twice with the same extraction solvent. The three organic phases were collected into a vial and concentrated under a nitrogen stream. Calibration curves were made using standard solutions of linalool, geraniol, nerol, citronellol, citral, $\alpha$-terpineol (Sigma-Aldrich), and rose oxide (Fluka).
Table 1 Wines and codes used in the work

\begin{tabular}{llllll}
\hline & 2013 harvest & & & 2014 harvest & \\
\cline { 2 - 3 } $\begin{array}{c}\text { Muscat Blanc "à } \\
\text { petit grains" }\end{array}$ & Ripeness level 1 & Ripeness level 2 & & Ripeness level 1 & Ripeness level 2 \\
\hline \begin{tabular}{l} 
Red Muscat \\
\hline
\end{tabular} & MV E1_13 & MB E2_13 & & MB E1_14 & MB E2_14 \\
\hline
\end{tabular}


A liquid-liquid extraction was also followed for the extraction of esters and volatile fatty acids. Wine samples $(50 \mathrm{~mL})$ were acidified with $30 \% \mathrm{H}_{2} \mathrm{SO}_{4}$ prior to extraction and 3-octanol (in methanol solution) was added as internal standard. The extraction was performed three times with diethyl ether/hexane (50:50), stirring in a closed flask for $5 \mathrm{~min}$. The three organic phases were collected into a vial. Calibration curves were made using standard solutions of isoamyl acetate, 2-phenylethyl acetate, ethyl octanoate, hexanol, butyric acid, isobutyric acid, octanoic acid, dodecanoic acid (Sigma-Aldrich), 2-phenyletanol, hexyl acetate, ethyl lactate, and diethyl succinate (Merck).

A VARIAN 3900 gas chromatograph, coupled to a Flame Ionization Detector (FID) and with an automatic injector CP-8410 was used. After the liquid-liquid extraction procedure, $1 \mu \mathrm{L}$ of extract was injected in split/splitless mode, at $200{ }^{\circ} \mathrm{C}$ in FFAP capillary column $(50 \mathrm{~m} \times 0.22 \mathrm{~mm}$ i.d.; $0.2 \mu \mathrm{m}$ film thickness) using hydrogen as carrier gas. The oven temperature programme used was: $60{ }^{\circ} \mathrm{C}(5 \mathrm{~min})-3{ }^{\circ} \mathrm{C} \mathrm{min}{ }^{-1}-200{ }^{\circ} \mathrm{C}$ (30 min). The FID temperature was set to $250{ }^{\circ} \mathrm{C}$.

\section{Extraction and GC-FID analysis of higher alcohols, methanol, acetaldehyde and ethyl acetate}

These compounds were extracted by simple distillation following the procedure recommended by the OIV (OIV, Compendium of International Analysis of MethodsOIV-Alcoholic strength by volume-Type IV methods-OIV-MA-AS312-01B, 2009). $100 \mathrm{~mL}$ of wine were measured in a volumetric flask and the temperature of the wine was recorded. The wine was transferred to the distillation flask and the volumetric flask was rinsed four times with $5 \mathrm{~mL}$ of water. Several ceramic pieces were added to the flask and about three-quarters of the initial volume of wine were collected into the same $100 \mathrm{~mL}$ volumetric flask. When the temperature of the distillate reached the initial temperature of the wine $\left( \pm 2{ }^{\circ} \mathrm{C}\right)$, the volume of the flask was completed with distilled water. Calibration curves were made using standard solutions of acetaldehyde, methanol, ethyl acetate, 1-propanol, 2-methyl-1-propanol, 2-methyl1-butanol, and 3-methyl-1-butanol (Merck).

Prior to injection on the GC, $50 \mu \mathrm{L}$ of 4-methyl-2-pentanol $\left(10 \mathrm{~g} \mathrm{~L}^{-1}\right.$ in a $40 \% \mathrm{v} / \mathrm{v}$ hydro alcoholic solution; internal standard) were added to $5 \mathrm{~mL}$ of distillate. A VARIAN CP-3380 gas chromatograph with a FID detector was used. The injections of the samples $(0.5 \mu \mathrm{L})$ were performed in split mode $(1: 30)$ at $220{ }^{\circ} \mathrm{C}$ in a $\mathrm{CP}$ wax $57 \mathrm{CB}$ column $(50 \mathrm{~m} \times 0.25 \mathrm{~mm}$ i.d.; $0.2 \mu \mathrm{m}$ film thickness $)$ using hydrogen as carrier gas. The oven temperature programme was: $40{ }^{\circ} \mathrm{C}(5 \mathrm{~min})-4{ }^{\circ} \mathrm{C} \mathrm{min}^{-1}-200{ }^{\circ} \mathrm{C}$, total time of $46 \mathrm{~min}$. The FID detector temperature was set to $220^{\circ} \mathrm{C}$.

\section{Colorimetric parameters}

Colorimetric parameters were measured in a NICOLET evolution 100 UV/VIS spectrophotometer using glass cells with $1 \mathrm{~cm}$ of optical path. Distilled water was used as blank. The colour parameters tint $(N)$, colour intensity $(I)$, clarity $\left(L^{*}\right)$, chroma $\left(C^{*}\right)$, and tone $\left(H^{*}\right)$ were calculated following the recommended procedures of OIV (OIV, Chromatic Characteristics-Method OIV-MA-AS2-07B, 2009b) (OIV, Determination of chromatic characteristicsMethod OIV-MA-AS2-11, 2006).

\section{Sensory analysis}

A sensory (aromatic and gustatory) comparison of the wines was performed. The sensory analysis panel consisted of ten trained judges with experience on wine sensory evaluation. All wines were presented at random coded order (three digit number - ISO 8587:2006) in black wine tasting glasses, so that the tasters were not influenced by the wine colour. Tastings were conducted in a specialised sensory evaluation laboratory at room temperature $\left(19 \pm 2{ }^{\circ} \mathrm{C}\right)$. Mineral water was provided for rinsing the mouth between wines. Judges were instructed to rate the intensity of each pre-defined attribute and of any free designated attribute on a 0 to 5 scale (0: not perceptible; 5 : strongly perceptible) for the aromatic profile analysis. For the gustatory profile analysis, a scale of 1 to 5 was used where 1 meant very insufficient, 3 adequate, and 5 excessive.

\section{Statistical analysis}

A Principal Component Analysis (PCA) of the chemical parameters (using a varimax rotation method with Kaiser normalization) was performed using SPSS version 22. The mean ratings and Fisher's Least Significant Differences (LSD) for each sensory descriptor were calculated by the analysis of variance (ANOVA) using the same version of SPSS.

\section{Results}

\section{Aromatic composition of the wines}

Table 2 characterizes the musts obtained from the two Muscat varieties. As expected, the ripeness level 2 of the grapes (E2) originated less acidic (lower total acidity and higher $\mathrm{pH}$ values) and higher sugar content musts than the ripeness level 1 (E1) in both varieties. The sugar content of Muscat Blanc "à petit grains" musts was higher than in the red variety, but the final levels of sugar and ethanol were similar in all wines, that being achieved by the control of 
Table 2 Chemical basic parameters of the musts (average values and relative standard deviations)

\begin{tabular}{lllll}
\hline Must & $\begin{array}{l}\text { Probable ethanol } \\
\text { content }(\% \mathrm{v} / \mathrm{v})\end{array}$ & $\begin{array}{l}\text { Sugar content (total solu- } \\
\left.\text { ble solids in }{ }^{\circ} \text { Baumé }\right)\end{array}$ & $\mathrm{pH}$ & Total acidity $\left(\mathrm{g} \mathrm{L}^{-1}\right)$ \\
\hline MB E1_13* & $11.6 \pm 0.0$ & $11.5 \pm 0.1$ & $3.25 \pm 0.01$ & $6.49 \pm 0.06$ \\
MV E1_13 & $11.3 \pm 0.0$ & $11.2 \pm 0.0$ & $3.26 \pm 0.01$ & $6.92 \pm 0.08$ \\
MB E2_13 & $12.8 \pm 0.0$ & $12.4 \pm 0.0$ & $3.22 \pm 0.01$ & $5.96 \pm 0.06$ \\
MV E2_13 & $11.7 \pm 0.1$ & $11.5 \pm 0.1$ & $3.25 \pm 0.01$ & $5.53 \pm 0.03$ \\
MB E1_14 & $12.9 \pm 0.1$ & $12.5 \pm 0.1$ & $3.23 \pm 0.01$ & $7.80 \pm 0.00$ \\
MV E1_14 & $11.9 \pm 0.0$ & $11.7 \pm 0.0$ & $3.25 \pm 0.01$ & $7.35 \pm 0.06$ \\
MB E2_14 & $13.4 \pm 0.1$ & $13.0 \pm 0.1$ & $3.50 \pm 0.00$ & $5.73 \pm 0.04$ \\
MV E2_14 & $12.8 \pm 0.0$ & $12.4 \pm 0.0$ & $3.46 \pm 0.01$ & $5.95 \pm 0.07$ \\
\hline
\end{tabular}

*See code and wine matches in Table 1
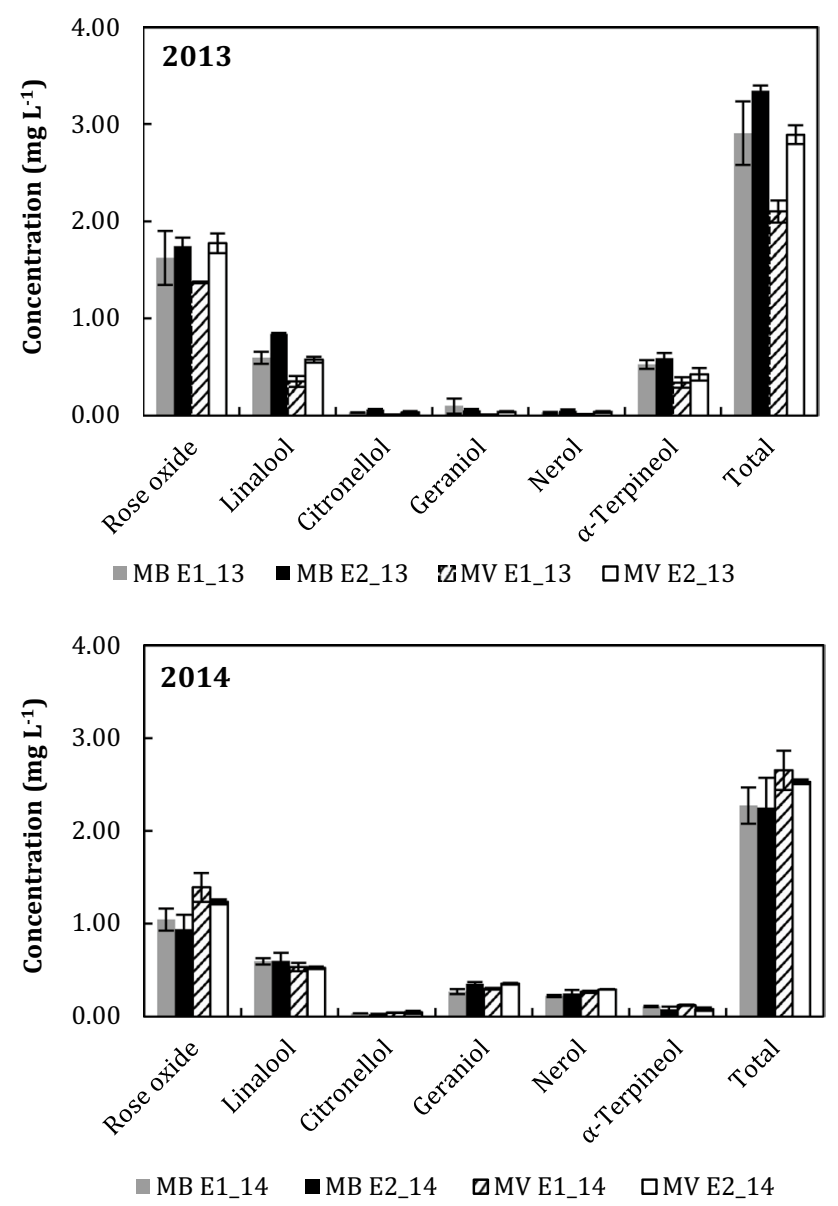

Fig. 1 Concentration of free monoterpenes $\left(\mathrm{mg} \mathrm{L}^{-1}\right)$ and relative standard deviations in Muscat fortified wines (2013 and 2014 harvests)

the fermentation time and by the amount of brandy added to stop the fermentations.

The volatile composition of the wines is shown in Figs. 1, 2 and 3. The data presented are the mean values of two technological replicates. Rose oxide (sum of the
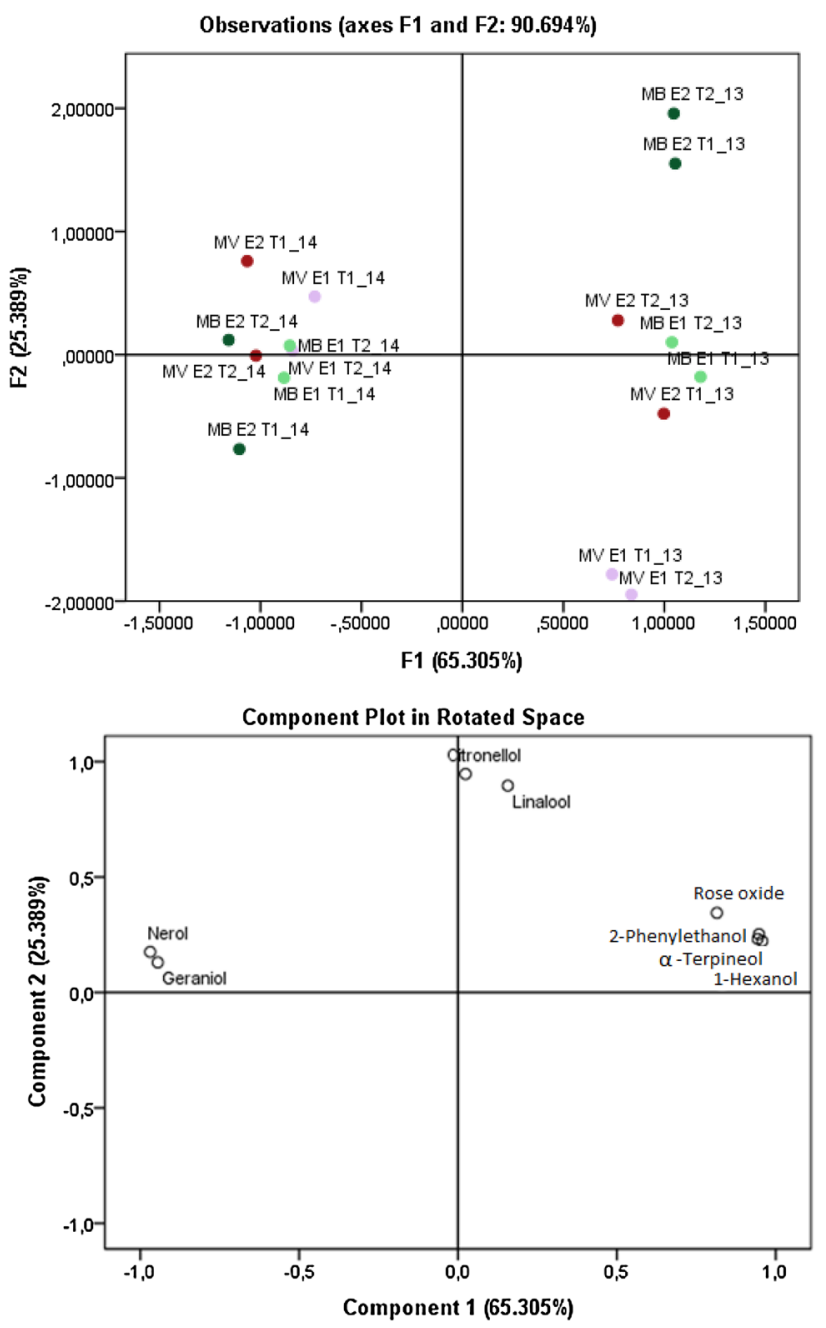

Fig. 2 PCA analysis for monoterpenes, 1-hexanol, and 2-phenylethanol. The first component explained $65.31 \%$ of the variance across the samples and the second component $25.39 \%$

isomers cis and trans) was the main terpenoid detected. Rose oxide, linalool, and geraniol were found above the odour perception thresholds (OPT) described in the 

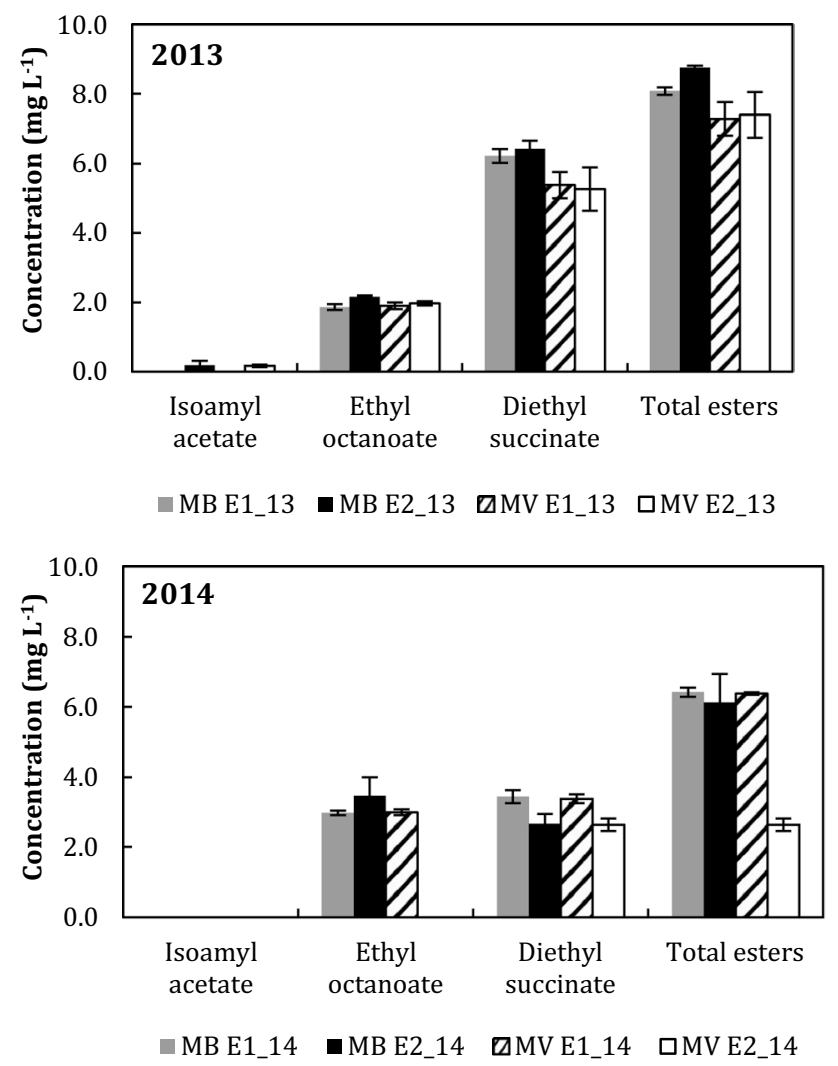

Fig. 3 Concentrations of free esters $\left(\mathrm{mg} \mathrm{L}^{-1}\right)$ and relative standard deviations in fortified Muscat wines (2013 and 2014 harvests)

literature: $0.2,25.2$ and $30 \mu \mathrm{g} \mathrm{L} \mathrm{L}^{-1}$, respectively (Fig. 1) $[16,17] . \alpha$-terpineol also exceeded its OPT $\left(250 \mu \mathrm{g} \mathrm{L}^{-1}\right)$ [18] in the 2013 wines. These compounds were also found to be present in other Muscat varieties, certainly playing an important role on the volatile profile of this type of wines [1, 3-5].

Geraniol and nerol were found at higher concentrations in the 2014 wines than in the 2013 wines (Fig. 1). The differences could be justified by the ageing effect ( 1 year period for the 2013 wines and 3 months for the 2014 wines). In other works, the concentrations of linalool, geraniol, and nerol were also found to decrease during a 1 year period of ageing, while $\alpha$-terpineol and rose oxide increased [7, 18].

The Principal Component Analysis (PCA) confirmed the differences between the 2013 and 2014 wines (Fig. 2), thus suggesting that the ageing influences the aromatic profile of the wines regardless of the grape variety or ripeness state. The grape ripeness level influenced the composition of the 2013 wines, MB E2, and MV E2 being richer in total monoterpenoids than MB E1 and MV E1 (Fig. 2). Citral was not detected in any of the samples.

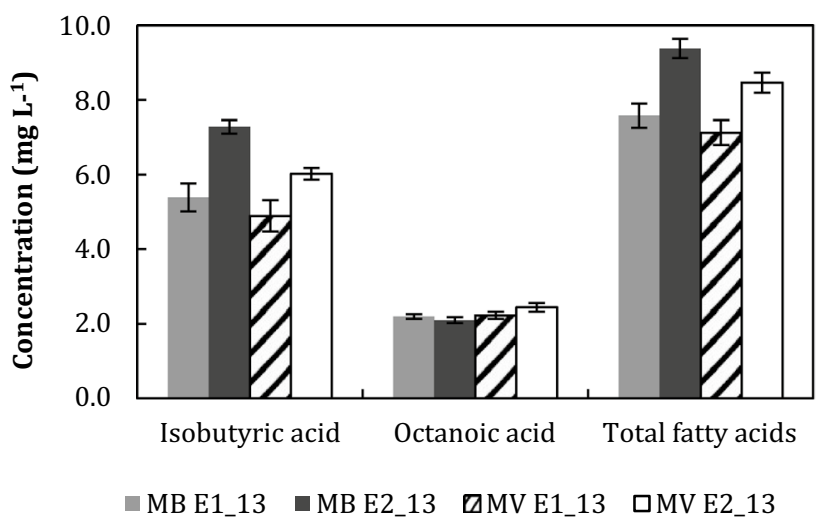

Fig. 4 Concentration of fatty acids $\left(\mathrm{mg} \mathrm{L}^{-1}\right)$ and relative standard deviations in the 2013 Muscat fortified wines

Regarding the esters composition (Fig. 3), ethyl octanoate and ethyl acetate were the only compounds that exceeded the OPT in all wines, 5 and $7.5 \mu \mathrm{g} \mathrm{L}^{-1}$, respectively $[16,17]$. Ethyl octanoate contributes with pineapple, pear, and floral aromas, while ethyl acetate may give a pleasant, fruity fragrance to the general wine aroma [12]. Isoamyl acetate, which has a characteristic banana aroma, was found above its OPT $\left(30 \mu \mathrm{g} \mathrm{L}^{-1}\right)$ [16] in both varieties of the 2013 wines, but only in those made from the ripest grapes. Diethyl succinate was present well below the OPT of $200 \mathrm{mg} \mathrm{L}^{-1}$ [19].

Octanoic acid is present in all wines in concentrations above the OPT (500 $\mu \mathrm{g} \mathrm{L}^{-1}$ ) [17]. This compound may be responsible for rancid and cheese aroma in some wines [11]. Isobutyric acid, which gives a phenol and fatty aroma [12], was found above its OPT $\left(2.30 \mu \mathrm{g} \mathrm{L}^{-1}\right)$ [17] in both varieties of the 2013 wines and at higher concentrations in wines produced from riper grapes (Fig. 4).

As the PCA shows, wines from the 2013 harvest possess higher levels of esters and fatty acids than the 2014 wines (Fig. 5). In the 2013 wines, it is possible to observe that the ripeness level E2 led to the formation of higher amounts of ethyl acetate and isobutyric acid in both varieties, which is confirmed by the PCA on Fig. 5.

Higher alcohols, originating either from the alcoholic fermentation or from the brandy added to stop the fermentation, usually contribute negatively to the wine aroma profile [20]. Isoamyl alcohol (3-methyl-1-butanol), with an OPT of $30 \mathrm{mg} \mathrm{L}^{-1}$ [16], imparting whiskey, malt, and burnt aromas [10], was the major alcohol found (219-256 mg L ${ }^{-1}$ ) (Fig. 6). Similar values were also found by other authors in Muscat Blanc "à petit grains" wines and in wines from other grape varieties [21]. Isobutanol (2-methyl-1-propanol) contributes to solvent and bitter aromas [10] and was found above its OPT of $40 \mathrm{mg} \mathrm{L}^{-1}$ [16]. 

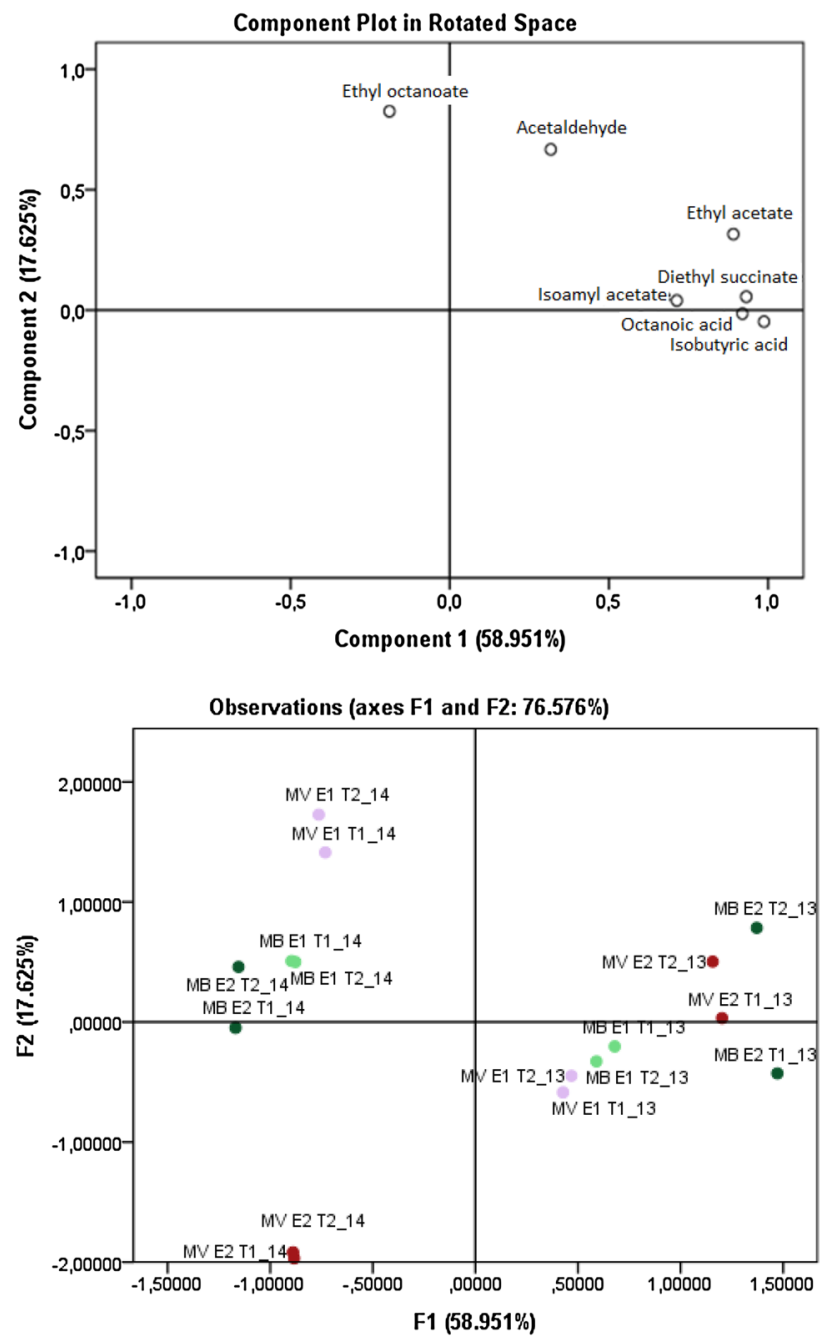

Fig. 5 PCA analysis for esters, fatty acids, and acetaldehyde. The first component explained $58.95 \%$ of the variance across the samples and the second component $17.63 \%$

1-propanol, which gives a fresh, alcohol aroma, is present below the OPT $\left(50 \mathrm{mg} \mathrm{L}^{-1}\right)$ [11] in both varieties of the 2013 wines. Hexanol, which contributes negatively to wine aroma (green, grass), was found in concentrations below its OPT $\left(8 \mathrm{mg} \mathrm{L}^{-1}\right)$. These alcohols were found at higher concentrations than previously reported for Muscat Blanc "à petit grains" probably due to the fortification of wines with brandy. 2-Phenylethanol, which contributes positively with flower aromas [11], was found in concentrations above its OPT $\left(10 \mathrm{mg} \mathrm{L}^{-1}\right)$ only on the 2013 wines. The Muscat Blanc "à petit grains" wines show higher amounts than the Red Muscat wines (Fig. 6). In the 2014 wines, the concentrations were below the OPT. Acetaldehyde, which gives a negative, oxidized apple aroma, was found well below its OPT (100-120 mg L ${ }^{-1}$ ) [22] in all wines studied (Fig. 6), in accordance with the levels found in other Muscat wines $[4,7]$.

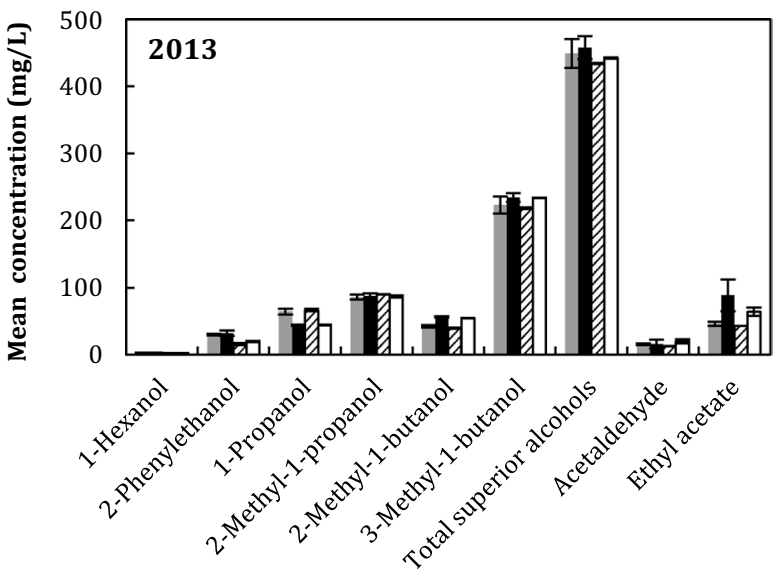

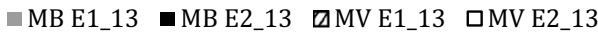

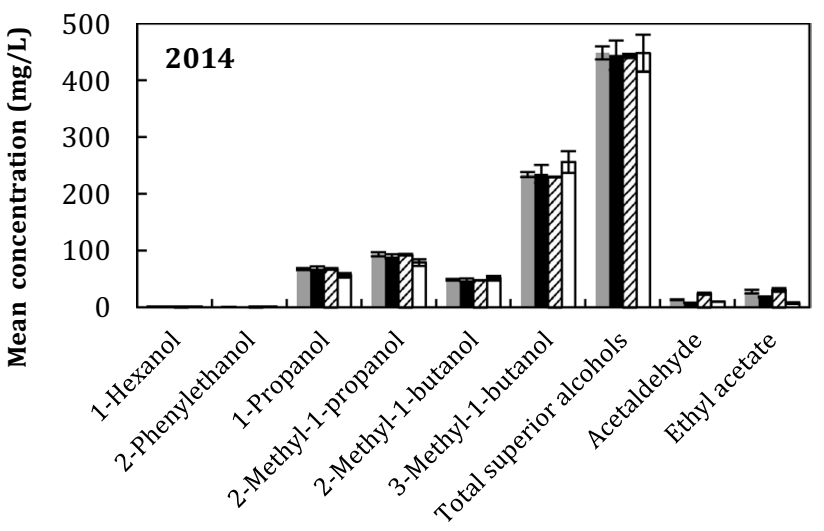

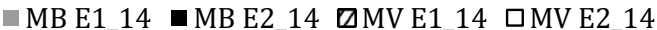

Fig. 6 Concentration of higher alcohols, acetaldehyde, and ethyl acetate $\left(\mathrm{mg} \mathrm{L}^{-1}\right)$ and the relative standard deviations in Muscat fortified wines (2013 and 2014 harvests)

\section{Colour characterization of the wines}

The chromatic characteristics of the wines were evaluated and the results are shown in Table 3. Both Muscat varieties have an orange tint $(N>1.2)$; however, the Red Muscat wines exhibit higher colour intensity $(I)$. Likewise, observing the chroma $\left(C^{*}\right)$ values of the 2014 wines, it can be concluded that Red Muscat wines have a more saturated colour. Clarity $\left(L^{*}\right)$ values show that Muscat Blanc wines are more luminous than the Red Muscat ones. As expected, Tone $\left(H^{*}\right)$ values demonstrate that Red Muscat have a more red colour (lower $H^{*}$ ) than the Muscat Blanc wines (Table 3). 
Table 3 Chromatic characteristics and relative standard deviations

\begin{tabular}{lccccc}
\hline & $N \pm \mathrm{SD}$ & $I \pm \mathrm{SD}$ & $L^{*} \pm \mathrm{SD}$ & $C^{*} \pm \mathrm{SD}$ & $H^{*} \pm \mathrm{SD}$ \\
\hline MB E1_13 & $2.334 \pm 0.008$ & $1.676 \pm 0.237$ & $75.3 \pm 2.4$ & $57.83 \pm 6.35$ & $74.70 \pm 1.46$ \\
MB E2_13 & $2.314 \pm 0.121$ & $1.337 \pm 0.291$ & $79.8 \pm 4.3$ & $51.86 \pm 7.16$ & $75.90 \pm 2.11$ \\
MV E1_13 & $2.112 \pm 0.065$ & $1.774 \pm 0.302$ & $72.8 \pm 3.8$ & $56.89 \pm 7.27$ & $70.43 \pm 1.67$ \\
MV E2_13 & $1.897 \pm 0.112$ & $2.180 \pm 0.001$ & $67.1 \pm 0.6$ & $65.32 \pm 0.08$ & $66.63 \pm 1.34$ \\
MB E1_14 & $2.640 \pm 0.018$ & $1.369 \pm 0.015$ & $80.1 \pm 0.3$ & $49.45 \pm 0.16$ & $78.22 \pm 0.22$ \\
MB E2_14 & $2.676 \pm 0.011$ & $1.803 \pm 0.033$ & $74.7 \pm 0.5$ & $56.02 \pm 0.35$ & $77.10 \pm 0.20$ \\
MV E1_14 & $2.022 \pm 0.006$ & $2.777 \pm 0.023$ & $58.4 \pm 0.3$ & $58.78 \pm 0.11$ & $67.42 \pm 0.21$ \\
MV E2_14 & $2.364 \pm 0.002$ & $2.453 \pm 0.025$ & $66.1 \pm 0.3$ & $65.58 \pm 0.14$ & $70.67 \pm 0.01$
\end{tabular}

Fig. 7 Descriptive sensory analysis of wines (mean scores of ten assessors). Aroma profile scored in a scale from 0 to 5 ( 0 not perceptible; 5 strongly perceptible); gustatory profile scored in a scale from 1 to 5 ( 1 very insufficient, 3 adequate, 5 excessive) and least significant differences (LSD, $p>0.05$ )
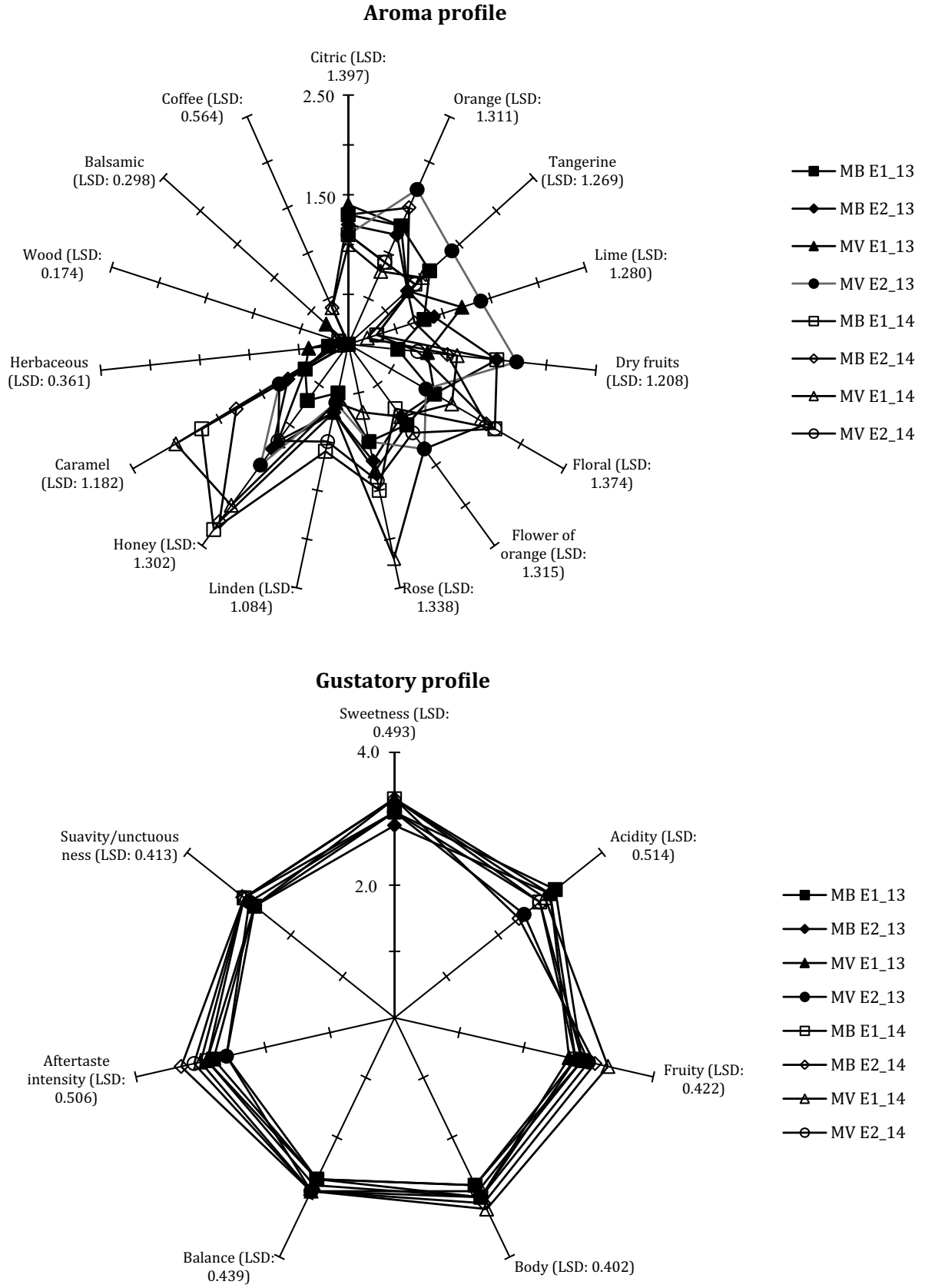


\section{Sensory analysis of the wines}

The main aroma descriptors detected in the wines were caramel, honey, rose, floral, dried fruits, lime, tangerine, citric, and orange (Fig. 7). The highest global classification was for wine MB E2_14, but no statistic difference was found between this wine and the Red Muscat wines from the same harvest year. In general, the 2013 wines were perceived as more fruity and the 2014 wines as more floral. The 2014 wines, especially from less ripe grapes, had stronger caramel aromas, although the difference between the ripeness levels is only significant $(p<0.05)$ for the Red Muscat 2014 wines.

Regarding the gustatory profile, the following parameters: balance, body, fruitiness, acidity, sweetness, and unctuousness were analysed (Fig. 7). MV E2_13 and MB E2_14 wines were rated as having insufficient acidity (2.5 and 2.4, respectively) and MV E1_14 was rated as the most fruity wine. There are no significant differences for the other gustatory attributes $(p>0.05)$ between the different wines tasted.

\section{Discussion}

Comparing the monoterpenoid composition of the two grape varieties, only rose oxide has a significant difference, appearing with greater concentration for the 2014 Red Muscat wines. However, in 2013, the Muscat Blanc "à petit grains" wines are richer in terpenoids (mainly linalool and $\alpha$-terpineol) than the Red Muscat. The ripening of the grapes seems to have a little influence in the monoterpenoid composition of the wines. As for the esters studied, only the diethyl succinate shows a significant difference, appearing in greater concentrations on the 2013 Muscat Blanc "à petit grains" wines. Of the higher alcohols analysed, only the 2-phenyl ethanol presents a significant difference, appearing in greater concentration on the 2013 Muscat Blanc "à petit grains" wines. In general, the 2013 wines are richer in esters and higher alcohols than 2014 wines.

The blind sensory analysis revealed no significant differences between wines for the different parameters evaluated. Two Red Muscat wines (MV E1_14 and MVE2_14) and one Muscat Blanc "à petit grains" wine (MB E2_14) were rated with the highest scores. On the olfactory examination, the 2013 wines were perceived as being more fruity and the 2014 wines as more floral, which is in accordance with the results of the chemical analysis.

This work gives a major contribution for the knowledge of a poorly characterized grape variety (Red Muscat), uncovering the main similarities and differentiating aspects in comparison with Muscat Blanc "à petit grains". The results show that the Red Muscat grape variety is suitable for the production of quality Muscat fortified wines; in addition, it shows potential for the creation of new styles of wines. In addition to its aromatic and gustatory profiles, the colour is an important differentiating aspect that can be exploited by the wine industry. The lower Clarity $\left(L^{*}\right)$ values found on the Red Muscat can be explained by the higher amount of light-absorbing pigments in this wine in comparison to the Muscat Blanc variety. This parameter is, however, not very relevant for the visually perceived colour "tipicity" of wines, which should be more related to the colour intensity and tonality of the wines. The data collected may support authorization applications for the use of the Red Muscat grape variety in the production of fortified Muscat wine.

Acknowledgements This work was supported by the National Funds from FCT-Fundação para a Ciência e Tecnologia through project UID/Multi/50016/2013. The authors thank IAPMEI-Agência para a Competitividade e Inovação, for the financial support under the project Vale Inovação 39928.

\section{Compliance with ethical standards}

Conflict of interest The authors declare that they have no conflict of interest.

Compliance with Ethics Requirements This article does not contain any studies with human or animal subjects.

\section{References}

1. Karagiannis S, Economou A, Lanaridis P (2000) Phenolic and volatile composition of wines made from Vitis vinifera $\mathrm{Cv}$. Muscat Lefko grapes from the island of Samos. Eur Food Res Technol 48:5369-5375

2. Selli S, Cabaroglu T, Canbas A, Erten H, Nurgel C (2003) Effect of skin contact on the aroma composition of the musts of Vitis vinifera L. cv. Muscat of Bornova and Narince grown in Turkey. Food Chem 81:341-347

3. Selli S, Canbas A, Cabaroglu T, Erten H, Günata Z (2006) Aroma components of cv. Muscat of Bornova wines and influence of skin contact treatment. Food Chem 94:319-326

4. Palomo ES, Pérez-Coello M, Díaz-Maroto M, Viñas MG, Cabezudo M (2006) Contribution of free and glycosidically-bound volatile compounds to the aroma of muscat "a petit grains"' wines and effect of skin contact. Food Chem 95:279-289

5. Sánchez-Palomo E, Alañón M, Díaz-Maroto M, González-Viñas M, Pérez-Coello M (2009) Comparison of extraction methods for volatile compounds of Muscat grape juice. Talanta 79:871-876

6. Fenoll J, Manso A, Hellín P, Ruis L, Flores P (2009) Changes in the aromatic composition of the Vitis vinifera grape Muscat Hamburg during ripening. Food Chem 114:420-428

7. Bordiga M, Rinaldi M, Locatelli M, Piana G, Travaglia F, Coïsson JD, Arlorio M (2013) Characterization of Muscat wines aroma evolution using comprehensive gas chromatography followed by a post-analytic approach to $2 \mathrm{D}$ contour plots comparison. Food Chem 140:57-67 
8. Ruiz-García L, Hellín P, Flores P, Fenoll J (2014) Prediction of Muscat aroma in table grape by analysis of rose oxide. Food Chem 154:151-157

9. Luan F, Mosandl A, Münch A, Wüst M (2005) Metabolism of geraniol in grape berry mesocarp of Vitis vinifera L.cv. Scheurebe: demonstration of stereoselective reduction, E/Zisomerization, oxidation and glycosylation. Phytochemistry 66:295-303

10. Francis I, Newton J (2005) Determining wine aroma from compositional data. Aust J Grape Wine Res 11:114-126

11. Li H, Tao Y-S, Wang H, Zhang L (2008) Impact odorants of Chardonnay dry white wine from Changli County (China). Eur Food Res Technol 227:287-292

12. Tao Y-S, Li H (2009) Active volatiles of cabernet sauvignon wine from Changli Country. Health (London) 1:176-182

13. Vilanova M, Genisheva Z, Graña M, Oliveira J (2013) Determination of odorants in varietal wines from international grape cultivars (Vitis vinifera) grown in NW Spain. S Afr J Enol Vitic 34: 212-222

14. Ünal MÜ, Aksoy VA, Sener A (2014) Isolation, purification and determination of some biochemical properties of $\beta$-glucosidase from Muscat of Bornova grape. Eur Food Res Technol 238:9-15

15. Degu A, Morcia C, Tumino G, Hochberg U, Toubiana D, Mattivi F, Schneider A, Bosca P, Cattivelli L, Terzi V, Fait A (2015) Metabolite profiling elucidates communalities and differences in the polyphenol biosynthetic pathways of red and white Muscat genotypes. Plant Physiol Biochem 86:24-33
16. Guth H (1997) Quantitation and sensory studies of character impact odorants of different white wine varieties. J Agric Food Chem 45:3027-3032

17. Ferreira V, López R, Cacho RF (2000) Quantitative determination of the odorants of young red wines from different grape varieties. J Sci Food Agric 80:1659-1667

18. Usseglio-Tomasset L (1983) Influence de la temperature de conservation sur les caractéristiques physico-chimiques et organoleptiques des vins (vins aromatiques). Bulletin de l'OIV 623: 19-34

19. Cullere L, Escudero A, Cacho J, Ferreira V (2004) Gas chromatograpgy-olfactory and chemical qualitative study of the aroma of six premium quality Spanish aged red wines J Agri. Food Chem 52: pp 1653-1660

20. Hazelwood LA, Daran J-M, van Maris AJ, Pronk JT, Dickinson JR (2008) The ehrlich pathway for fusel alcohol production: a century of research on Saccharomyces cerevisiae metabolism. Appl Environ Microb 74:2259-2266

21. Bavčar D, Baša Česnik H, Čuš F, Košmerl T (2011) The influence of skin contact during alcoholic fermentation on the aroma composition of Ribolla Gialla and malvasia istriana Vitis vinifera (L.) grape wines. Int J Food Sci Technol 46:1801-1808

22. Fugelsang KC, Edwards CG (2007) Wine microbiology, practical applications and procedures, 2 edn. Springer, New York 